\title{
Access to Electronic Information: Challenges and Initiatives
}

\section{Author}

\section{Jayasuriya, Sumana}

PGDip, in LIS (The Philippines), MLS (The Philippines), Hon.

Fellow of the SLLA

Librarian, University of Colombo, Sri Lanka

\section{Contact Detals}

E-Mail: scj@cmb.ac.lk

Tell: 00-94-11-2586432/2414183

Fax: 00-94-11-2583043

\section{Abstract}

Managing and providing access to electronic information is one of the major challenges faced by the university librarians. The article presents a brief overview of the changes which are taking place in the information environment due to technological developments, and the impact these changes have had on scholarly communication. It also points out the key issues i.e. organizational, managerial, technical, infrastructure, financial, 
archiving, and user issues faced by university librarians when providing access to electronic information. It concludes by summarizing the initiatives taken by Sri Lankan universities in this regard.

\section{Keywords: Electronic information; academic libraries; university libraries, Sri Lanka}

\section{Introduction:}

Libraries facilitate the selecting, producing, providing access to, identifying, retrieving, organizing, providing instruction in the use of, and preserving recorded expression regardless of the format or the technology. The mission of the university library is to meet the teaching, learning, scholarly, research, and other information needs of their faculty, students, and affiliates, and to do so effectively and efficiently.

With the introduction of technology, the ways in which the materials are assembled, organized, and described has changed. These changes involve cost of computing power, data storage costs, and technology of communication, and other related costs. The mission of the library remains the same but the means of using them have changed due to this shift. Hence the library is expected to redesign its' services for users to make effective use of the online materials.

"Electronic or E-information is defined as a broad term that encompasses abstracting and indexing services, electronic journals and other full text materials, the offering of information aggregators, article delivery services etc. E-information can be 
accessed via remote networks from information providers, or locally mounted by a consortium or one it its member libraries" (ICOLO).

The nature of electronic information is such that it flows across boundaries and barriers despite attempts by individuals, governments, and organizations to control it. Even so, many people are not able to have access due to technology, infrastructure or economic reasons.

The characteristics of electronic documents differ greatly from those of paper documents:

- An electronic document can be used from anywhere, without one even knowing where it is stored geographically depending on the availability of telecommunication connections.

- In practice several people can use the same database or electronic records at the same time.

- Electronic documents are easily copied.

- Documents stored electronically are very flexible. They are easy to revise, rearrange, reformat, and combine with other documents. Hence the popularity of word-processing among people who have to create and, more especially, revise documents.

- Collections of documents stored in electronic form are now less bulky than paper versions. The trend is to even greater compactness.

- Change in information handling habits. Library centered view to user centered view.

- Trend to digitize everything for storage and manipulation sound, image, moving images, text and numeric data 
- Bring service to potential users.

Because of these reasons, electronic documents are becoming increasingly important and arrangements to provide access to them must be developed and is best viewed as an addition to the library services. This additional form of library service appears to be not only desirable for library users but also inevitable. As such, library services will have to provide access to paper documents and to electronic documents according to their users' needs. The balance between paper documents and electronic documents can be expected to vary widely between libraries and over time, but the libraries have to ensure that they are equipped to provide access to both kinds of document.

\section{Change in scholarly communication}

There is an increasing volume of academic journal publication particularly in science, technology and medicine due to authors publishing more and more for their promotions in universities. Scholarly communication has been defined by Shaughnessy (1989) as "the social phenomenon whereby intellectual and creative activity is passed from one scholar to another". Scholars use various ways to communicate and publishing in reputed journals is one major mode of scholarly communication. The scholarly communication system is one large complex system comprising of authors, academic libraries, publishers, and learned societies. Academic library is one link of this system.

Hogan (2001) concluded that a crisis has emerged as a result of rapid and continuous global change in the economic and political spheres and the development and expansion of new technologies. There has been an exponential growth of specialized information and computers have 
revolutionized the way it is used. As a response to this 'crisis' in the scholarly communication, academic libraries have now begun a determined move to provide e- access to information to their client communities.

Milne (1999) concluded that impact of funding agencies affected all other areas of scholarly communication and academic libraries turn toward technology based systems to cope up with this crisis. Milne also found that academics from three traditional areas of scholarship science, social science, and humanities displayed distinct differences in the patterns of use of electronic information. Electronic journals have provided scholars with an expedited and expanded mode of communication.

There was a time when e-journals were considered as ephemeral and inaccessible but now accepted as a viable substitute for print journal. Shamp (1992) found that academics found electronic publishing as a means of communicating research findings rather than to advance careers. Lancaster (1995) pointed out that library directors and academic administrators favoured the idea of networked scholarly publishing but university administrators were less certain that universities would soon be able to overcome the administrative and financial barriers to establishing such a system. However the fact that universities and reputed publishers have become involved in electronic journals certainly gives credibility to the medium, and it has been accepted as a popular vehicle for scholarly communication. 


\section{Challenges}

There are several challenges connected with the provision of access to einformation which should be addressed by academic libraries.

\section{User issues}

The user environment is not confined to four walls of the library and the librarians must now teach the faculty and the students about home resources, and also point to the existence of, and means to access the vast aggregate of global material. The students will be overwhelmed by the plethora of resources and searching tools in the changing electronic library, and majority of them cannot function well unaided.

A common misconception among users is that information available via web is all free. Pinfield (2001) found out that many undergraduate students were not aware of the fact that internet work in different domains and what is delivered through internet is not all free. Because e-content is free at the point of use and easily accessible to users on campus, they forget that it comes at a price.

When university web pages offer links to a huge array of well managed, high quality information resources for students, academic staff and researchers, the assumption is that the LIS staff members who assemble these possess the skills and knowledge. Whether the academics or students have the knowledge or skills to use these resources effectively is a big question. 
There are several problems faced by the students when using eresources. Determining accuracy and authenticity of electronic information pose special problems to users. Navigating through vast aggregate of information, it is up to the user to determine what is appropriate. Evaluating and sorting good information (useful, relevant, reliable) from bad (unreliable, false, extraneous) need knowledge and skills which need to be taught to users. There is a lack of suitable on-line material for very specialized courses, as free and commercial gateways of hubs do not normally cater to specialized subject areas. The impermanence of online material is another problem. Students become frustrated if they cannot find the web site they referred to for the second time. Oversupply of online material from which to make choices, and the students' poor information seeking and evaluative skills are some of the problems identified. Evidence has shown that individuals fail to identify accurately their learning needs, locate relevant resources, evaluate the utility of such resources, evolve their strategies, and conduct a successful search. These are precisely the skills needed to successfully engage many resource based approaches.

Acquisition of resources is not enough, but universities must make sure that access is provided to students. Libraries when deciding to move to e-resources should consider how it impact on users, levels and ease of use of e-resources, and how researchers go about finding information they need in the e-context. The users may become frustrated if they have to use different search interfaces, and difficulty of browsing can be a frustrating experience. Students need to be directed and sometimes information access needs to be filtered, so that access is only to relevant and quality information. Sometimes proliferation of information can become a barrier to their access and use. Librarians must make a 
determined move to establish dissemination routes to make online resources available. These can be made available through library websites, providing one-to-one help sessions for students and academics, feed back mechanisms, telephone help lines and staff training by library staff.

Users need assistance in navigating e-resources. They must be shown ways to identify quality resources. The users especially the undergraduate students depend heavily on the web and the information they get should always be the quality ones.

High-quality information may be difficult to access because of poorly designed web sites or associated fees. In addition, each web-based resource seems to hold such a vast quantity of information that it is easy to assume that one has conducted a comprehensive search, when, in fact, other resources contain unique, relevant information. It is too easy to violate copyright on the web. Finally, web-based resources cannot be browsed like their print counterparts. Some users enjoy browsing among the book shelves.

Librarians can help users by becoming partners in literature searches and by teaching effective searching strategies. Librarians can teach better information seeking techniques, including how to use controlled vocabularies and how to evaluate information on the web, and guide users to search multiple web-based resources to more thoroughly cover a given topic and to complement web-based resources with print resources, which contain much scholarly information that is not duplicated on the web. Librarians can also make users aware of tools that are available to assist the use of web-based resources. For example, 
subject directories help to cut through the information overload on the web and more quickly find relevant and high-quality information. Database selection tools help to find relevant databases for their research. Navigation of e-journal web sites can be eased or eliminated by linking software.

\section{Infrastructure}

Libraries can deliver e-services only in the context of wider ICT based provision. This requires a heterogeneous hardware and software environment which lay a heavy emphasis on compatibility, linking and interoperability through standardized protocols. Therefore, libraries have to rely on infrastructure, hardware and expertise provided by computing services in the universities. Partnership between libraries and computer centres are a necessity and these partnerships vary from institution to institution. What ever the form this relationship takes, it is vital if users are to be served properly. Greater team and project working, flatter structures, improved communication channels are some of the key areas in which this relationship is based.

Development of infrastructure to enable users to make use of the facilities should be in place, campuses be networked adhering to national and international standards so that there is compatibility between machined crossing service boundaries. A culture change is possible only when desk top access is provided to end users.

\section{Systems and technical issues}

This is one of the major challenges faced by the librarians. Several projects have been carried out in United Kingdom to conceptualize the 
role of the library in the hybrid information environment. Many libraries have developed their web sites to be gateways to information resources available to users. They provide direct links to e-journals, CD-ROMs, and quality web resources, in addition to the OPAC.

Integration of many different types of data such as statistical, graphical, sound, moving images, and creating a navigable online library environment has become a big challenge for librarians. Designing ways of navigating wide range of resources is also a major challenge. This is made possible by the use of various cross-searching and cross-linking technologies and many projects are being undertaken to develop this facility.

Another major technical issue is authentication, authorization and security. Most institutions use IP-range authentication. As off-campus access is becoming increasingly important to many users, some institutions have set up proxy servers.

Personalization becomes an ongoing challenge for those libraries planning to develop portal-type facilities for their users to cover a wide range of services than just the e-library.

\section{Administrative issues}

While budgets of the libraries kept on the decrease, academics and other users expect libraries to maintain print based services parallel with electronic services and this could be an expensive exercise. Libraries are expected to provide these with existing funding. 
The increasing prices of printed journals, growing volume, cost, and diversity of scholarly information will require continuing investment in subject and language expertise and professional skills to select, organize, service, and preserve this information.

Many electronic products come as cross-disciplinary packages, very few would be subject specific. Allocations are divided among the faculties taking into consideration various factors such as student numbers, staff numbers, number of courses, prices of material etc. When such formulae are used to divide up the allocation librarians are faced with the difficulty of selecting the most appropriate resources to be acquired for the library. The specialized subject resources will be expensive, and the library may not have sufficient funds to provide access to all specialized ones, where as the general resources may have some titles which are not essential. Therefore, libraries must have the flexibility to respond to available deals with the publishers on behalf of users.

When shifting from traditional library to automated library, librarians may need to re-examine the priorities in staff time. Libraries are spending large amounts of money on traditional library operations such as cataloguing, circulations etc. There are other issues such as user support services they have to give priority in an e-environment. Hence some of the positions may be redundant while new positions may have to be created.

\section{Collection development}

As much as libraries have to develop the infrastructure to deliver econtent, a collection has to be developed to cover all media. Einformation has to fit into overall collection, and there has to be a 
balance between print and e-resources. Librarian has to decide which print resources should be replaced by e-resources. Providing connections to global information, services and networks is not the same as selecting and purchasing material for a library collection. Each library will have materials selected considering the needs of the clientele. The collection development policy should include the criteria for selection, training and support implications, procedures for acquisition, evaluating content and functionality of e-resources.

Acquisition procedures have to be amended to involve liaising with suppliers, organizing trials and demonstrations, formal evaluation, negotiating prices, licensing for off-campus and multi-campus access to materials.

Once acquired, e-information has to be managed continuously because packages seem to add and subtract titles on regular basis, and there is also problem of access. Since materials in electronic form lend themselves to remote access and shared use, coordinated collection development and cooperative shared access to collection becomes important.

\section{Service practices:}

Expanded library service seems likely to depend more and more on facilitating self service rather than one-on-one service by library staff. However, the latter will remain necessary and desirable even though the tasks facing the library users are becoming more complex. When there is increasing complexity, problems arise in searching and retrieving materials and user's expertise is inadequate for this task. To alleviate 
these problems the library could adopt several measures depending on the needs of the users. These measures will range from user education, advice, simplification, mediation and delegation.

Reference service could include library instruction, and referral services. The changes in the provision of the library services affect the users in what they do, and changes in the tasks and work habits of library users affect the provision of library services. The library will enhance their services by providing access to materials available inside and outside the library. New tools provide powerful options to the user when using web access. Library staff should provide answers to queries from users about web access, and understanding about remote resources.

\section{Access to e-journals}

There are different ways of accessing e-journals. These can be accessed from publisher's website as a single title or as part of a package, for free or on a subscription basis. Sometimes they are made available through subscription agents. Services by subscription agents such as Swets Navigator, or Ebsco Online provide a unified entry point for electronic journals and offer a common interface. Searching facilities and access to abstract information is often available across all the titles offered by the service but to gain access to full text articles, subscription to individual titles are required. They also can be made available thorough one or more aggregator services.

Aggregator services provide access to packages of full text data. The advantage it offers to the librarian is that it provides access to a greater range of titles for a lower price than it would cost to subscribing each 
journal title individually. Full text access is generally integrated with indexing and searching functionality. Content is maintained at the provider's own site, sometimes it may be loaded locally at the subscriber's site. E.g. Academic Search Premier, ABI Inform Global, Proquest 500 (Gatenby, 2000). It is also correct to say that some of the titles offered by these services have very low or no use for the users.

Academic publishers operating in e-environment are trying to maintain or increase their market shares and profits and this has led to a crisis situation in this area. Publishers have shown a trend towards locking their content away in subscription based databases.

Current pricing models of e-information are ill-affordable by academic libraries, and will not be able to sustain in the long run. Today's einformation products are not fully formed or stable but fibraries have to bear the cost. Currently prevailing e-journal model is 'current print price + e-surcharge + significantly projected inflation charges'. Hence libraries need usage statistics in order to make informed decisions.

Measuring usage of periodicals have been always difficult, this is more difficult in e-environment. Usage statistics need to be sought from publisher or aggregator. Not all publishers provide statistics and there is little uniformity in what is provided as measure of usage. One of the major concerns libraries are facing is to measure the usage of eresources. Who uses them? And, to what extent? Have the right ones been purchased?

There is a need for libraries to establish preferred practices with regard to contract negotiations, pricing, access, archiving, systems and licenses, content \& management of data and use, authentication etc. 
According to Pinfield (2001) although many e-journal packages provide access to additional titles, they involve at least $7 \%$ on to of existing print expenditure. He suggests many options for librarians to overcome this crisis. Some of the options are to negotiate vigorously with publishers, journal editors to work with publishers with regard to pricing, possibility of creating cross-searchable databases of research papers and make them available freely on the web.

As libraries have traditionally managed information resources, they should be the institutions to hold e-print servers. Librarian should take the role of raising awareness about these amongst their academic colleagues and institutional managers. They need to establish a dialogue with academics to address these issues and take the advocacy role seriously.

\section{Archiving and preservation}

Archiving of information is critical as e-information do not provide the degree of permanence offered by print collections. If not managed properly e-information can be highly transient. To prevent loss of information and allow users to access back files libraries must ensure preservation in appropriate formats of information obtained electronically.

There is an ongoing debate as who has the responsibility of preserving einformation. Is it the senior staff of the library or the publishers? The national agencies can play a big role in this context. Galvin, (2004) state that questions about responsibility for archiving, preservation and 
continued access to information started to arise as libraries began to purchase journals from the aggregators. He says,

\begin{abstract}
"The model of ficensing (access rather than ownership) carries peculiar questions. If a library cancels a license with a publisher or aggregator, will they still have access to the literature for which they paid licensing fees? Does the vendor actually guarantee that the literature will remain forever accessible?"
\end{abstract}

He further states that in order to assist librarians many agencies such the Council on Library and Information Resources (CLIR), Association of Research Libraries (ARL), Higher Education Funding Council of UK have been working on model licensing agreements, creating guidelines, etc. In the past, archiving was the responsibility of libraries, but the question today is not about preserving physical materials, but of continuing to make information accessible.

\title{
Activities of professional associations
}

Many professional organizations realizing the impact of electronic information on free access, copyright issues, has taken initiatives to focus on implications and applications of e-information in libraries. El-media offer an unprecedented forum for sharing of information, and ideas. Libraries being a part of national information infrastructure harvest this opportunity to provide free access to e-information services and networks. Resources in e-form are increasingly recognized as vital to the provision of information that is the core of the library's role in society. ALA considering the complexities of the e-information environment has focused its attention to three main areas which can impact on society. 
These areas are rights of users, equity of access, and information resources and access.

\section{Initiatives by Sri Lankan universities}

Flatten (1997) in his article "Five things to change first when academic libraries embrace web access" say that in the process of change from print to web access changes in five areas i.e. attitudes, infrastructure, staff skills, appearances, and service practices are imperative.

At the beginning there is apprehension and doubt from managers and professional staff with regard to the cost. The management must have a positive attitude and should not consider this as a threat to the limited finances. They have to accept the fact that the world is in the middle of electronic communications revolution. Today publishers act globally to provide electronic information and it is incumbent upon librarians to act globally to provide this information.

This change requires endless requirement to upgrade staff skills, followed on from the constant upgrades of IT. Learning new skills, build confidence and positive attitudes among the staff and this make further learning possible. Changing the image of libraries as places of access for print and electronic information need to be promoted, web mediation and services to be introduced, and signage changed to reffect the provision of web access.

Are Sri Lankan universities ready to go forward? Lanka Educational, Academic and Research Network (LEARN) was established in 1990 to interconnect Educational and $R$ \& $D$ institutions across the country to provide a regular data communication service. Funds for this venture were provided by the Swedish government through its aid agency Sida. 
The first e-mail service in Sri Lanka, LEARN-mail, operated by the Department of Computer Science and Engineering, University of Moratuwa was the beginning of the series of services provided through LEARN. This facilitated the member institutions with dial-up e-mail service. LEARN has brought together the academic and research scientists through e-mail service, served as a gateway to the outside world by providing international access to peer level scientists, databases and other networked resources on the internet. It has also served as the technology enabler in the country and had been the test bed for many new developments. At present LEARN is managed by a committee appointed by the University Grants Commission. In 1995, LEARN obtained direct internet access through Sri Lanka Telecom (SLT), a government owned business enterprise. With the enactment of Telecommunication Act No. 25 of 1991, number of private companies providing various telecommunication services increased rapidly.

At present, major universities are served with internet access through LEARN, and establishment of campus wide networks have been completed in some of the universities and others are in progress. Computer facilities in libraries are upgraded. Some of the issues which need to be addressed urgently is insufficient bandwidth, infrastructure improvements, and recruitment or training of skilled staff.

Provision of access to electronic information began in 2002 through sponsorship of International Network for the Availability of Scientific Publications (INASP). INASP has been the foreign collaborator for Sida funded library support project for many years, and through its PERI initiative provided island wide access to four electronic databases: Blackwell Publishers (Synergy), EBSCO Host, John Wiley \& Sons 
(InterScience), British Library Inside Web Service (Current Awareness Service), and BLDSC (Document Delivery Service). Training of trainer workshop was held in 2002 to train librarians in the use of electronic databases, and these librarians were expected to conduct training workshops in the effective use of e-resources for their users, mainly academic staff and under-graduates.

When libraries are making transition from print to electronic media, they have been forming consortia to acquire access to e-resources particularly to major aggregator services. University libraries having realized the importance of consortia have formed a consortium in 2003 with the aim "To obtain access to electronic information resources through collective acquisitions which will lead to cost effectiveness, wider usage of current information and expansion of research activities". It had the following objectives:

- Identify and access relevant electronic information resources for targeted user groups

- Promote use of electronic resources for information update and to build research capacity

- Develop strategies to share resources, introduce current awareness services and archiving relevant materials

The university of Peradeniya library has been selected as the focal point of this consortium and steps have been taken to organize demonstrations from publishers, and aggregator services, to agree on the resources to be acquired. 
In a continuously evolving e-environment, LIS Professionals are required to take on a wider variety of roles requiring a range of skills than ever before. Library managers need to address the issue of how staff are obtained, trained and retained in order to carry out this work. The difficulties of changing staff structures, creating new positions, seem to be a general problem across the university sector where traditional roles are favoured by the administration. Libraries are expected to be fast moving innovative organizations working together with academics to provide an effective service to users. University librarians need to play a pro-active role to convince the authorities of the need for this change. Web-based resources present possibilities as well as problems. However, with the right strategies and tools, academics and librarians can make the most of web-based information.

\section{References}

ALA Interpretations: Questions and answers: Access to electronic information, services, and networks: an interpretation of the Library Bill of

Rights' http://www.ala.org/PrinterTemplate.cfm?section=interpretation\&Templat $\mathrm{e}=/$ Content $\ldots . .30 .11 .2004$

Flatten, Kay. (1997) 'Five things to change first when academic libraries embrace web access' Information Research, 3(2) Available at: http://informationr.net/ir/3-2/paper40,html

Galvin, Jean. (2004) 'The next step in scholarly communication: is the journal dead?' Electronic Journal of academic and Special Librarianship $5: 1$ Available

at: http://southernlibrarianship.icaap.org/content/v05n01/galvin j01.htm 
Gatenby, Pam (2000) 'Provision of access to journals in electronic form: issues for libraries and the role of the National Library of Australia' a paper presented at the National Library of Australia, Collecting Advisory Committee (CAC) meeting, 11 December 2000, NLA, Canberra. Available at: http://www.nla.gov.au/staffpaper/pgatenby $3 \mathrm{html}$

Hogan, Tom (2001) 'Drexel University moves aggressively from print to electronic access for journais'. Computers in Libraries 21:22-27

Milne, Patricia (1999) 'Electronic access to information and its impact on scholarly communication' paper presented at the Information Online \& On Disc 19-21 January 1999

http://www.csu.edu.au/special/online99/proceedings99/305b.htm

International Coalition of Library Consortia (ICOLC) 'Statement of current perspective and preferred practices for the selection and purchase of electronic information' http://www/library/yale.edu/consortia/statement.html p.1

Lancaster, F. W.(1995) 'Attitudes in academia toward feasibility and desirability of networked scholarly publishing'. Library Trends 43:515-517

Milne, Patricia.(1999) 'Electronic access to information and its impact on scholarly communication' http://www.csu.edu.au/pecial/online99/proceedings99/3056b.htm 
Pinfield, Stephen (2001) 'Managing electronic library services: current issues in UK higher education institutions' Available at:

http://www.aridane.ac.uk/issue29/pinfield/intro.html last modified $\underline{12.10 .2004}$

Shamp, Scott (1997) 'Prospects for electronic publishing in communication: a survey of potential users'. Communication Quarterly 40: $297-304$

Shaugnessy, Thomas W. (1989) 'Scholarly communication: the need for an agenda for action - a symposium'. The Journal of Academic Librarianship 15: p. 68. 